Revista Educação e Políticas em Debate - v. 10, n. 1, p. 433-452, jan./abr. 2021 - ISSN 2238-8346

\title{
Avaliação, Plano Nacional de Educação de 2014 - 2024 e as interpretações acerca da Meta 7
}

\author{
Evaluation, National Education Plan 2014 - 2024 and interpretations about Goal 7 \\ Évaluation, Plan national d'éducation 2014-2024 et interprétations de l'objectif 7
}

\author{
José Márcio Silva Barbosa ${ }^{1}$ \\ Universidade do Estado de Minas Gerais \\ Rita Márcia Andrade Vaz de Mello² \\ Universidade Federal de Viçosa
}

Resumo: No presente estudo, tomamos como base a análise documental do índice de Desenvolvimento da Educação Básica, meta 7, do Plano Nacional de Educação, objetivamos discutir acerca de suas implicações na gestão da educação pública. Preocupados em eximir o Estado de sua responsabilidade pelos baixos índices do sistema de avaliação do ensino público e escassos investimentos na educação pública, evidenciamos que há dúvidas se o índice tem sido considerado um indicador suficiente para realmente avaliar a qualidade em educação. $\mathrm{O}$ discurso sobre o rendimento escolar do aluno face à gestão por resultado cria a imagem de que a Escola tem conseguido resolver todos os seus problemas e situações conflituosas no seu espaço e que nela se reproduz a lógica do capital global em vigor.

Palavras-chave: Avaliação. Plano Nacional de Educação. Ideb. Gestão por resultados.

Abstract: In the present study, we take as a base the documentary analysis of the Basic Education Development index, goal 7, of the National Education Plan, we aim to discuss about its implications in the management of public education. Concerned with relieving the State of its responsibility for the low indexes of the public education evaluation system and scarce investments in public education, we show that there are doubts as to whether the index has been considered a sufficient indicator to really evaluate the quality of education. The discourse on the student's academic performance vis-à-vis management by results creates the image that the School has managed to solve all its problems and conflicting situations in its space and that the logic of the global capital in force is reproduced in it.

Keywords: Evaluation. National Education Plan. Ideb. Results-based management.

Résumé: Dans la présente étude, nous prenons comme base l'analyse documentaire de l'indice de développement de l'éducation de base, objectif 7 , du Plan national d'éducation, nous visons à discuter de ses implications dans la gestion de l'enseignement public. Soucieux de décharger l'État de sa responsabilité à l'égard des faibles indices du système d'évaluation de l'enseignement public et des investissements limités dans l'enseignement public, nous

\footnotetext{
${ }^{1}$ Professor da Universidade do Estado de Minas Gerais (UEMG). Doutor em Educação pela Universidade Federal de Minas Gerais (UFMG). E-mail: jose.barbosa@uemg.br. Lattes: http://lattes.cnpq.br/0795475468886946. ORCID: https://orcid.org/O000-0003-4582-5009.

2 Professora do Departamento de Educação da Universidade Federal de Viçosa (UFV). Pós-doutorado e doutora em Educação pela Universidade Federal de Minas Gerais (UFMG). E-mail: ritamarciamello@gmail.com. Lattes: http://lattes.cnpq.br/6268124799372996. ORCID: https://orcid.org/o000-0002-7473-9559.
} 
Revista Educação e Políticas em Debate - v. 10, n. 1, p. 433-452, jan./abr. 2021 - ISSN 2238-8346

montrons qu'il existe des doutes quant à la question de savoir si l'indice a été considéré comme un indicateur suffisant pour réellement évaluer la qualité de l'éducation. Le discours sur la performance académique de l'élève vis-à-vis de la gestion par les résultats crée l'image que l'École a réussi à résoudre tous ses problèmes et situations conflictuelles dans son espace et que la logique du capital mondial en vigueur s'y reproduit.

Mots-clés: Évaluation. Plan national d'éducation. Ideb. Gestion axée sur les résultats.

\section{Introdução}

O Plano Nacional de Educação (PNE), instituído pela Lei $\mathrm{n}^{\circ} 13.005$ de 2014, trouxe novos contornos para a educação brasileira. Ao estabelecer as 20 metas a serem atingidas pelas instituições de ensino, bem como suas respectivas estratégias, o documento em análise tem sido o instrumento que orienta a execução e o aprimoramento de políticas pública em Educação e aborda questões relevantes. Nesse sentido, Cury (2008, p. 1.204) sinalizou questões relevantes, ao afirmar que "um sistema de educação supõe, como definição, uma rede de órgãos, de instituições escolares e de estabelecimentos - fato; um ordenamento jurídico com leis de educação - norma; uma finalidade comum - valor; uma base comum - direito”.

A despeito dessas recomendações, a avaliação sobre a realidade educacional brasileira é, sem dúvida, a principal ferramenta posta a serviço dos governos para a elaboração de políticas educacionais, que têm levado em consideração o desempenho dos estudantes em exames padronizados. Diante disso, uma de suas polêmicas está voltada à discussão sobre a ampliação dos instrumentos de aferição de resultados.

A começar pela meta 7 do PNE, que abarca questões relacionadas ao Índice de Desenvolvimento da Educação Básica (Ideb) como um dos principais indicadores da qualidade da Educação Básica, o referido índice pretende comparar e avaliar o rendimento do sistema de ensino com melhoria no fluxo escolar e da aprendizagem, de acordo com os padrões pré-estabelecidos para o acompanhamento do desempenho dos estudantes, da escola e de seus profissionais. Em linhas gerais, o índice foi criado com o propósito de tornar possível o monitoramento de escolas com alunos de baixo desempenho.

Ressaltando a preocupação com os resultados dessas avaliações, a grande questão que se apresenta para nós, neste momento, é: qual é a lógica e o discurso que está por trás do Ideb? Em que medida a meta 7 do PNE (2014 - 2024) aponta para a importância de integrar 
Revista Educação e Políticas em Debate - v. 10, n. 1, p. 433-452, jan./abr. 2021 - ISSN 2238-8346 a gestão das escolas públicas na busca por resultados significativos, de forma a assegurar a elevação do nível de desempenho dos estudantes?

Ao que tudo indica, o sobredito índice tem apresentado alterações radicais no quadro de toda a gestão da escola, gerando inúmeras e infindáveis polêmicas. Havendo diversas interpretações a respeito desse assunto, este trabalho apresenta e analisa as tensões referentes à meta 7 no PNE (2014-2024) de modo a atingir determinados parâmetros, dentre os quais o Ideb.

O objetivo é discutir as recomendações propostas pelo Plano e apresentar as interpretações acerca de suas implicações na gestão da educação pública. Especificamente, importa que se tenha uma visão mais apurada dessa tendência na qual a educação brasileira está imergindo e o que realmente é valorizado pelas políticas de avaliação educacional pelo Estado.

O estudo constitui-se da abordagem qualitativa de caráter exploratório e análise documental como estratégia metodológica a fim de conectarmos, na produção científica dos acadêmicos, as especificidades recorrentes à compreensão do tema. Neste texto, as diretrizes do PNE se ancoram nos documentos disponíveis no site do MEC.

Além da introdução e das considerações finais, o desenvolvimento do texto exigiu tecer algumas considerações: a primeira delas busca compreender algumas evidências sobre o sentido da avaliação educacional. A segunda refere-se ao Plano Nacional de Educação e ao tratamento dado ao indicador Ideb. A terceira questiona a relação entre gestão por resultados e trabalho docente.

\section{Avaliação educacional: algumas evidências}

Os debates sobre a avaliação educacional adquirem centralidade na literatura contemporânea. Poderíamos considerar que ela intensifica no desenvolvimento de políticas educacionais sob o argumento de que "a valorização governamental da avaliação como instrumento de controle da aprendizagem e diagnóstico do ensino, se torna cada vez mais evidente, o que aparece com preponderância no Plano Nacional de Educação (PNE) atual” (FERREIRA, 2016, p. 411).

Em relação aos estudos prévios que analisam a evolução da avaliação educacional, essa tem sido um campo de diversos significados e sentidos para sua mensuração, o que nos coloca o desafio de interpretação. No caso da avaliação, um sistema educativo tem várias facetas. É sobre a avaliação da aprendizagem que há aspectos que precisam ser mencionados, focando-se na análise crítica das atuais trajetórias da avaliação educacional.

A começar por Figueiredo (2009, p. 1125), a autora vem justificar a reforma educacional pela "falta de qualidade, de produtividade e de requerimentos educacionais 
necessários à modernização do país e à integração à globalização, sob o argumento de que se deve alcançar a eficiência nos gastos públicos e na qualidade na educação”.

É que a implementação de ajustes no setor educacional, como corolário, anunciou a avaliação como um processo e uma condição necessária para que se possam estabelecer e acompanhar metas qualitativas e quantitativas e verificar se essas serão atingidas. Com esse olhar,

A avaliação é capaz de fomentar nas escolas e nas redes uma interpelação sistemática sobre a qualidade de suas práticas e dos seus resultados, articulando os contributos da avaliação externa com a cultura e os dispositivos de autoavaliação das escolas, bem como reforçando a capacidade das escolas de desenvolver sua autonomia, no intuito de regular o funcionamento do sistema educativo (ALAVARSE, BRAVO, MACHADO, 2013, p. 25).

Os autores observaram que a centralização dos esforços oficiais, por mais que o Estado busque dar respostas à crise de seus sistemas educativos, foi justificada como necessária no monitoramento do funcionamento das redes de ensino, visando fornecer aos seus gestores subsídios para a implementação de políticas educacionais com focos mais bem definidos em termos de resultados educacionais, os quais, por sua vez, decorreriam das aprendizagens dos alunos e, portanto, passariam para um nível de diagnóstico, de operacionalização e de avaliação da educação.

Nos anos 1990, a agenda das políticas educacionais de toda a América Latina foi marcada por uma sucessão de ações orientadas para aferir o aprendizado dos alunos por meio de aplicação de testes de proficiência a estudantes de escolas públicas e privadas. A análise das proficiências das avaliações externas por meio dos níveis de aprendizagem inclui, entre outros, uma forma de analisar o desempenho de cada aluno visando o ensino de melhor qualidade.

De modo mais específico, as propostas que se apresentaram como "inovadoras" (TORRES, 1996, p. 371, grifo da autora) no campo educacional nos últimos anos conferem a questão principal do neoliberalismo. Ainda nesse sentido, destaca-se que "em termos de protagonismo da agenda de políticas educacionais, a estreita vinculação entre os setores que produzem os textos (os Bancos) e os Estados Nação” (TELLO; ALMEIDA, 2014, p. 166). Nesse quesito, os autores enfatizam que nos referidos documentos, emergem noções que constroem e constituem significados sobre a categoria da profissionalização docente tais como: autonomia docente e salário e incentivos aos papéis do docente e da sua relação com os diretores de escolas, pais e alunos.

Diante de tal contexto, os autores foram mais explícitos ao afirmar que: a lógica mercantilista dos Bancos, ao apregoar que a profissionalização docente, em termos de resultados por meio do BID, um avanço para os estabelecimentos escolares, enxergando na implantação do Índice de Desenvolvimento Educativo Básico (Ideb), no ano de 2007: 
Um mecanismo de avaliação de melhoria da aprendizagem por meio de um sistema efetivo de prestação de contas, de forma que a preocupação com a eficiência do trabalho docente, inserida numa lógica racionalizadora, técnica e pragmática que se encontra na defesa abstrata da capacidade de adaptação, na rapidez nas respostas e na busca por solução de problemas cotidianos da escola e na habilidade em responder às demandas de pais, alunos e gestores (TELLO; ALMEIDA, 2014, p. 168).

Assim sendo, podemos observar que no que diz respeito aos contextos locais, as experiências escolares do docente, sob o desempenho dos alunos, sugerem múltiplas abrangências e enfoques para a solução de problemas da escola.

A era dos testes padronizados nacionais e internacionais relacionados à aprendizagem escolar nos sistemas educacionais direcionou a atenção para que o papel desempenhado pelos professores nesses resultados, qualquer que seja o seu nível de qualidade, uma vez que a formação de professores seria um fator contribuinte para esses resultados (ÁVALOS, 2014, p. 15).

Dentre elas, ressalta-se nos processos de autonomia escolar e na criação de conselhos escolares ou nos colegiados, com participação dos professores, da família e dos alunos "maior rapidez, eficiência e redução de gastos na resolução de questões de várias ordens, como na manutenção e na melhoria da infraestrutura, dos equipamentos e do material pedagógico da escola quando assumidas pela comunidade local” (SANTOS, 2004, p.1149).

Embora a avaliação deva ser desenvolvida pelos professores, Mancebo (2007, p. 471) afirma que “a submissão das instituições e dos docentes a rigorosos e múltiplos sistemas avaliativos e suas implementações, nos quais se destacam as avaliações gerenciais, abrangem o controle do sistema educativo por parte de um núcleo central". Há de se considerar, portanto, que tais avaliações têm implicações diretas na sua gestão, pelo menos no que tange à melhoria da oferta educacional, tendo por sua vez, na objetivação da eficiência do professor e de sua produtividade em índices, a provocação para viabilizar seu trabalho a um conjunto de medidas que condiciona o aumento dos indicadores de produtividade (MANCEBO, 2007).

Neste sentido, o Brasil vinha investindo no desempenho das avaliações, com critérios que envolvem, no caso da rede pública de ensino, resultados significativos para alavancar o desenvolvimento de processos pedagógicos e de gestão escolar, configurando impactos desejáveis à escola. Nesse contexto, ao relembrarmos brevemente o histórico das avaliações de desempenho, a criação de um Sistema de Avaliação da Educação Básica (Saeb), nos anos 1990, serviu de referência para apoiar a maioria dos estados e municípios, na elaboração de suas próprias metodologias para a avaliação de desempenho.

Argumenta-se que essa política de avaliação foi desenvolvida, visando demonstrar a situação da Educação Básica no Brasil por meio do levantamento de informações nas 
Revista Educação e Políticas em Debate - v. 10, n. 1, p. 433-452, jan./abr. 2021 - ISSN 2238-8346

diversas escolas do país. Vale ressaltar também que por intermédio do Instituto Nacional de Estudos e Pesquisas Educacionais Anísio Teixeira, Inep, o Saeb tem o propósito de diagnosticar o quadro do sistema educacional brasileiro, identificando os fatores que possam propor questões e informações sobre o desempenho dos alunos, fornecendo dados sobre a qualidade da educação oferecida à população.

Atualmente, existe um reconhecimento por parte do governo brasileiro, especificamente, no que se refere ao andamento das políticas públicas pela análise do desempenho dos alunos sobre o esforço de um novo projeto inovador na educação, mediante a abrangência do processo avaliativo e produtor de índices em questão. Embora possa parecer ter obtido avanços significativos,

No caso brasileiro, os governos Fernando Henrique Cardoso (FHC) e Luiz
Inácio Lula da Silva não conseguiram erradicar o analfabetismo no País.
Além disso, o crescimento do analfabetismo funcional e os índices de evasão
e repetência continuaram os mais elevados do mundo. O fracasso escolar é
assustador e as avaliações externas como o SAEB, Prova Brasil e ENEM
acumularam sucessivamente baixos índices de rendimento escolar entre
1995 e 2007 (FERNANDES NETO, 2009, p.15).

Com efeito, o país passou a considerar que a educação passava por uma crise nos sistemas de ensino e a necessidade de uma mudança na atuação do Ministério da Educação apresentarem uma análise das circunstâncias em relação aos Ensinos Fundamental e Médio no que diz respeito ao processo de ensino e aprendizagem dos alunos aquilo que vem sendo definido como indicadores de bom desempenho.

Percebemos que a leitura feita pelos estados brasileiros tem demonstrado que a avaliação em larga escala, é hoje tão necessária nas instituições escolares que intensificou a preocupação em obter bons resultados a partir de métodos estatísticos para a consolidação de um quadro geral de ação política, como se fossem extensivos a todas as escolas. Essa tendência vem sendo incorporada a novas formas de gerir a escola, no intuito de melhorar a eficiência dos sistemas de ensino e fomentar a responsabilidade profissional pelos resultados a serem alcançados na escola. Todavia, ainda carece de amplo debate, dadas as generalizações ainda presentes.

Compreendemos que, hoje em dia, qualquer discussão sobre avaliação tem constituído em implicações na gestão da escola e no trabalho dos profissionais da educação, principalmente quando a avaliação busca medir e informar o que realmente acontece na escola, principalmente no plano de aprendizagem dos alunos. Os pressupostos que têm inspirado as experiências de avaliação que se quer imprimir na implementação de políticas educacionais no Brasil é o PNE, numa clara indicação do caráter desejável que assume, dentre outras, a introdução de sua meta 7 . 
Revista Educação e Políticas em Debate - v. 10, n. 1, p. 433-452, jan./abr. 2021 - ISSN 2238-8346

\section{Plano Nacional de Educação 2014 - 2024 e o Índice de Desenvolvimento da Educação Básica no contexto brasileiro - Meta 7}

A educação nacional passou a contar com o novo Plano Nacional de educação (PNE) como um dos principais instrumentos das políticas educacionais brasileira para a década iniciada em 2014 e com vigência até 2024. Por meio das 20 metas, cada qual acompanhada de informações sobre suas respectivas estratégias, projeta-se contribuir para que o país avance na democratização da educação, na universalização do ensino e no direito à educação a todos brasileiros.

Um dos exemplos marcantes é representado pelo Plano ao estabelecer em seu artigo 8, inciso II, que "os processos de elaboração e de adequação dos planos de educação dos estados, do Distrito Federal e dos municípios, serão realizados com ampla participação de representantes da comunidade educacional e da sociedade civil” (BRASIL, 2014; s/p).

Não obstante, é importante também registrar, nesse quadro, ao estimular o favorecimento de escolas para melhorar seu desempenho, tem-se o estímulo a avaliação da qualidade por meio de índices que vêm trazendo às escolas a tentativas de padrões de qualidade. A prerrogativa que visa ampliar a ampla mobilização e participação desse processo em construção, tem-se no Índice de Desenvolvimento da Educação Básica (Ideb) a responsabilidade de articular com os sistemas de ensino à melhoria do fluxo escolar e, sobretudo, da aprendizagem dos estudantes, em articulação das avaliações nacionais com as iniciativas subnacionais.

É no contexto dessas novas orientações que os entes federativos, União, Distrito Federal, Estados e Municípios deverão se articular, por meio de diferentes estratégias e mecanismos, no âmbito do regime de colaboração para garantir o alcance do nível suficiente de aprendizado, nas médias nacionais previstas para o Ideb. Isso equivale a dizer que "as orientações para o sistema de avaliação seguem amplo processo de diagnóstico da situação educacional no país, objetivando alcançar a meta de 6,0, estipulada para as próximas décadas” (BRASIL, MEC, 2014, s/p).

Na tabela a seguir, apresentamos a indicação das médias nacionais do Ideb.

Tabela 1: Médias Nacionais do Ideb

\begin{tabular}{|l|c|c|c|c|}
\hline \multicolumn{1}{|c|}{ Ideb } & 2015 & 2017 & 2019 & 2021 \\
\hline $\begin{array}{l}\text { Anos iniciais do Ensino } \\
\text { Fundamental }\end{array}$ & 5,2 & 5,5 & 5,7 & 6,0 \\
\hline Anos finais do Ensino Fundamental & 4,7 & 5,0 & 5,2 & 5,5 \\
\hline Ensino Médio & 4,3 & 4,7 & 5,0 & 5,2 \\
\hline
\end{tabular}

Fonte: Relatório do PNE/Inep, 2019 
Revista Educação e Políticas em Debate - v. 10, n. 1, p. 433-452, jan./abr. 2021 - ISSN 2238-8346

Conforme ilustrado na Tabela 1, a meta 7 do PNE propõe o aumento gradativo do índice em todas as etapas e as modalidades do ensino da Educação Básica de modo a atingir as seguintes médias nacionais para o Ideb até 202 1: “6,0 nos anos iniciais do ensino fundamental; 5,5 nos anos finais do ensino fundamental; 5,2 no ensino médio” (BRASIL, MEC, 2014, s/p).

Infere-se, dessa maneira, que, por considerar um conjunto de estratégias para o cumprimento da meta 7 , é preciso ressaltar que tais propostas que compõem o indicador a cada nível de ensino, tem no observatório do PNE lançado em 2013, as informações e extenso acervo de estudos, entre outras questões abordadas sobre o Plano, visando o monitoramento dos principais acontecimentos e materialização de sua vigência.

Trata-se de um projeto de advocacy (OBSERVATÓRIO do PNE, s/p, 2020), que visa facilitar o acompanhamento do cumprimento do Plano por intermédio das informações provindas do Censo Escolar e do Inep. Dessa perspectiva, o monitoramento auxilia os responsáveis pela formulação e pela implementação de políticas públicas ou pelo direcionamento de recursos públicos a entenderem melhor a coleta de dados e dos resultados do dia a dia da Educação Básica. Assim, será possível monitorar o que está acontecendo para que o aprendizado dos alunos alcance os resultados previstos no indicador Ideb, ao mesmo tempo, propor encaminhamentos aos problemas detectados e acompanhar sua implementação.

Por essa razão, é fundamental que cada estratégia, especialmente aquela relacionada a meta 7 do PNE indique o percurso que o índice tenha sido alcançado, destacando a Teoria da Resposta ao Item (TRI) para comparar os resultados alcançados ao longo do tempo e entre séries diferentes, expressos, geralmente, na Escala Saeb.

Disto decorre o predomínio de apoio à construção de políticas de repasse de recursos e apoio técnicos para orientar as ações com relação ao processo educativo da escola. Para Alavarse, Bravo e Machado (2015), em algumas redes públicas, foram desencadeadas políticas de remuneração diferenciada para profissionais da educação em função dos resultados dos alunos, consolidando um tipo de política chamada de responsabilização, fator que incrementa o debate em torno da avaliação educacional.

Conforme análise de Belo e Amaral (2013, p. 343), "as provas escolares que induzem a esse tipo de aferição, que são usualmente empregadas como única de adesão aos resultados demonstrados pelo Ideb". Compreende-se que o indicador identifica e tem de oferecer a resposta específica as redes e as escolas públicas mais frágeis. É importante que recebam maiores recursos financeiros e técnicos da União, na perspectiva de construir ações efetivas para promover a aprendizagem dos alunos. 
O índice é calculado pelo conhecimento do aluno, pautados na Prova Brasil e no Censo Escolar a partir de três conceitos: a aprovação, a evasão e a média obtida nas avaliações de Língua Portuguesa e Matemática. Este aspecto apresenta ainda a possibilidade de observar os dados das escolas brasileiras apresentados pelo IDEB, levando em consideração alguns fatores que podem estar por trás dos números que ilustram o "melhor desempenho" e o "pior desempenho" dos alunos (BELO; AMARAL, 2013, p. 343).

Cabe, ainda, ressaltar que o uso de testes padronizados permite monitorar a evolução do desempenho das redes escolares e de professores para se obter importantes informações a respeito do desempenho das escolas, visando o cumprimento da meta do IDEB.

Além deste fato ilustrado acima, Abreu (2018) afirma que medir o desempenho escolar não é tarefa fácil de ser realizada como a de identificar a taxa de atendimento escolar. Envolve todo um processo, vinculado à coerência e a percepção dos rumos, objetivos e das finalidades em que se baseiam a prática pedagógica. Mais uma vez Abreu (2018, p. 20) aposta na seguinte afirmação: "não basta apenas avaliar, pois uma escola não pode ser comparada com outra devido ao fato de que muitos fatores externos e internos interferem nos resultados".

Desse modo, "o governo passaria a se preocupar em coletar e divulgar estatísticas que retratassem o funcionamento do sistema educacional como um todo" como mostra Becker (2010, p. 1). O que o autor quer enfatizar aqui diz respeito ao uso do material coletado e em relação à divulgação dos resultados se faz necessário, o que na visão da autora, tais informações deverão "utilizar uma linguagem menos técnica, mais acessível a fim de serem previamente debatidos para que as provas e a metodologia a serem desenvolvidas atendam tais propósitos” (BECKER, 2010, p. 2).

Há de se considerar, também, a responsabilidade e a resposta sobre o contexto em que ocorre a atividade do trabalho docente, a partir da realidade que as constituem, o que implica ter em conta maior precisão sobre os problemas e deficiências que possam ser superados com base nos dados levantados. É necessário frisar que:

Assolado por cobranças de produtividade, eficiência, empreendedorismo,
criatividade, compromisso com a escola, o professor é obrigado a
desenvolver um senso de sobrevivência que, não raro, o transforma em um
sujeito competitivo que investe suas energias na tentativa de superar a
solidão, a culpa, o fracasso, a impotência, a incompetência e as incertezas.
Nessa seara, a lógica da produtividade encontra respaldo dando lugar à
ideia de que os bons resultados escolares independem da qualidade da
formação e dos salários dos professores da Educação Básica
(EVANGELISTA; SHIROMA, 2007, p. 537).

As contradições e as ambiguidades são inúmeras, dentre essas, Silva (2015, p. 15) lança um posicionamento que permite verificar se "a divulgação dos resultados das avaliações obtidas está sendo alcançado na educação, ou seja, se os alunos estão aprendendo”. Ao 
Revista Educação e Políticas em Debate - v. 10, n. 1, p. 433-452, jan./abr. 2021 - ISSN 2238-8346 considerar que a forma como tais resultados são apropriados nas escolas e a maneira como as mesmas trabalham para obter índices maiores nas avaliações é um elemento que merece destaque. Levando-se em conta a aferição do desempenho dos alunos, a autora ressalta que também chegou à escola a introdução de mecanismos de gestão por resultados, o que poderia ser potencializado pelo trabalho docente. Estudos que, sem alcançar consenso, discutem os efeitos positivos e negativos dos incentivos a sua implementação na área educacional.

Em face de tais considerações, o PNE vigente até o presente momento, ainda se apresenta como documento que analisam o alcance e a evolução suas metas e estratégias a fim de prover indicadores de rendimento escolar e da aprendizagem dos alunos acerca da educação como direito social público, cujas consequências se farão sentir por décadas no país.

\section{Gestão por resultados: um novo locus para trabalho docente?}

É na ideia de que o Ideb comunica a situação dos resultados dos processos de gestão e sinaliza o desempenho dos alunos na avaliação e no fluxo escolar que residem o debate atual sobre o índice enquanto propositor e mobilizador de políticas nas escolas públicas brasileiras. Em todos os casos, as mudanças que se quer incluir na escola de Educação Básica é a contratualização de resultados, incluindo o fortalecimento das avaliações.

É notória a discussão em torno do papel do professor frente aos desafios educacionais da atualidade e sua centralidade na obtenção de melhores resultados na escola. Essa categorização mostra o quanto a noção de gestão por resultados tem se tornado objeto de debates políticos. Nessa abordagem da gestão por resultados, a busca permanente pela qualidade e melhoria contínua da educação passa, pois, pela definição de padrões de desempenho e competências de diretores escolares, dentre outros, de modo a nortear e orientar seu desenvolvimento: "o termo utilizado para se medir a qualidade em educação passou a ser um desdobramento de monitoramento e de avaliação, com foco específico na participação da comunidade escolar, de modo a superar distorções e limitações em relação a seu caráter pedagógico e construtivo” (LÜCK, 2009, p. 43).

Muito embora a melhoria do desempenho esteja presente nas intenções políticas implementadas:

A formulação de uma política nacional de avaliação, explicitada pelo SAEB por exemplo, tem oferecido elementos para dimensionar os problemas relativos ao desempenho dos estudantes brasileiros, mostrando que há muito a ser feito para que o Brasil possa alinhar aos países que têm obtido êxito na promoção do sucesso escolar de seus alunos. Entretanto, o compromisso assumido pelo governo trouxe como instrumento de monitoramento das políticas, a gestão por resultados (VIEIRA, 2007, p. 50 - 51). 
Tal centralidade nas instituições escolares, Rodrigues (2009, p. 104) corrobora este pensamento ao afirmar que o desempenho do papel preponderante na elaboração de diagnósticos e nas respectivas estratégias pelos Organismos das Nações Unidas para a Educação, Ciência e Cultura (UNESCO) e a Comissão Econômica para a América Latina (CEPAL), trazem propostas visando compatibilizar as estratégias das agências de financiamento e as necessidades políticas dos governos.

No Brasil, repercutindo esse direcionamento, percebe-se que com as materializações do novo papel de fazer acontecer assumido pelo Ministério da Educação, "as ações básicas consubstanciam na centralização de políticas estratégicas visando a objetivos de controle e de constrangimento da autonomia pedagógica das escolas e dos sistemas de ensino" (RODRIGUES, 2009, p. 105-106). Intensificando as discussões, a visão de Gatti (2013) sugere uma resposta plausível ao nosso questionamento:

Podemos dizer que, subjacentemente, isso indica uma perspectiva produtivista em educação, que veio se acentuando cada vez mais. Sinaliza, também, para sua vinculação às pressões de organismos internacionais, especialmente os que favorecem financiamentos de diferentes ordens ao país e aponta para um modelo gerencialista que passa a modelar as propostas educacionais, com foco apenas nos resultados de rendimento escolar dos alunos (GATTI, 2013, p. 21).

Vale assinalar que parte importante desse processo reside:

$\mathrm{Na}$ sequência de políticas avaliativas estreitamente articuladas com o exercício do controle social por parte do Estado, pode igualmente ser referenciada à primeira fase do Estado-avaliador a introdução de mecanismos de accountability baseados em testes estandardizados de alto impacto e em rankings escolares, indutores de formas autoritárias de prestação de contas e de responsabilização das instituições, organizações e indivíduos, como tem sido o caso do programa No Child Left Behind (AFONSO, 2009, p. 272).

Considerando ainda as ponderações do autor supracitado, ele assevera que em grande parte dos discursos marcados por este viés político-ideológico, o significado do vocábulo accountability:

Indica frequentemente uma forma hierárquico-burocrática ou tecnocrática e gerencialista de prestação de contas que, pelo menos implicitamente, contém e dá ênfase a consequências ou imputações negativas e estigmatizantes, as quais, não raras vezes, consubstanciam formas autoritárias de responsabilização das instituições, organizações e indivíduos (AFONSO, 2012, p. 472).

Nesse cenário, os indicadores de qualidade passaram a ser medidos, dentre tantas outras justificativas, como os novos métodos de gerenciamento de sistemas educacionais. 
Revista Educação e Políticas em Debate - v. 10, n. 1, p. 433-452, jan./abr. 2021 - ISSN 2238-8346

Por sua vez, as medidas que se seguiram articulam-se com a necessidade de políticas de formação, haja vista que o Ministério da Educação (MEC) homologou o Parecer $\mathrm{CNE} / \mathrm{CP} n^{\circ}$ 22/2019, do Conselho Nacional de Educação (CNE), que atualiza as Diretrizes Curriculares Nacionais para a Formação Inicial de Professores para a Educação Básica e institui a Base Nacional Comum para a formação inicial de professores da Educação Básica denominada BNC-Formação, de forma abreviada, no documento. Atualmente regida por medidas que estão previstas em resolução de $\mathrm{n}^{\circ}$ 02/2019 do Conselho Nacional de Educação (CNE) e homologada pelo MEC pelos moldes da BNCCs, essa base passou a ser articulada para atender o imperativo das avaliações sistêmicas.

Em virtude disso, a formação dos professores no Brasil foi alongada, voltada exclusivamente as questões curriculares, que passou a ter maior foco na BNCC, para a educação escolar na etapa básica Infantil, Fundamental e Médio. Uma dessas retomadas seria a necessidade de preparar professores e diretores de escola na possibilidade de garantir um patamar de aprendizagem aos estudantes utilizando a base como instrumento.

Segundo Gatti (2014), a preocupação com a avaliação do desempenho escolar não estava voltada ao sistema escolar como um todo, mas apenas em relação àqueles que poderiam ou não adentrar em curso de nível universitário. De qualquer forma, foi nesse movimento que "alguns profissionais começaram a receber a formação mais aprofundada na área de avaliação de rendimento escolar, vinculada à teoria de medida e aos conhecimentos sobre elaboração de testes objetivos, sua validade e fidedignidade” (GATTI, 2014, p. 11).

Para superar deficiências na escola, criou-se a ideia de que seria necessário ter altos índices nos exames nacionais e internacionais, a fim de empreender esforços para conseguir atingir metas previstas nas políticas de avaliação. Certamente, as condições de trabalho dos professores e gestores escolares têm implicações no enfrentamento de problemas, situações do cotidiano da escola, que precisam ser vencidos.

Percebe-se, então, que a gestão escolar exerce papel fundamental na instituição responsável em difundir os resultados e criar mecanismo para atingir os resultados previstos pelo Ideb. Essa iniciativa se daria a uma nova mentalidade de ação no qual o foco principal de gestão está relacionado a questões internas da escola, por isso, é necessário que a escola na fase de ajuste e (re)construção para as demandas das provas sistêmicas concentrem esforços no diagnóstico, no controle e na busca de resultados.

Segundo Paschoalino (2017, p. 58), "nos moldes da gestão da escola, a qualidade passa a ser conduzida por avaliações que configuram o controle, a mensuração e as projeções para sua eficácia”. Nesta perspectiva, que as políticas públicas educacionais têm se respaldado no 
discurso da formação docente, visando a mobilização dos gestores para que alcancem as metas propostas, principalmente as relacionadas ao IDEB.

Diante dessas reflexões, o desafio de adotar práticas de gestão pela formulação política baseia-se nos critérios de eficiência e de eficácia dos atos e dos fatos organizacionais da escola, em face das novas reformas educativas que orientam a defesa de escola de qualidade. Por outro lado, questões conflituosas nas relações que se estabelecem entre gestores escolares e o trabalho realizado, deve ser sensível e crítico quanto as concepções diversas que envolvam a lógica produtivista e capitalista, que controlam os serviços educacionais prestados pelo Estado.

Portanto, diante de tantas mudanças na área educacional, principalmente quando pensamos em avaliações externas, cada estado passa a investir em seus sistemas de educação com políticas públicas capazes de alavancar os índices de avaliação e o quanto seria possível esperar dessa escola. Por isso, os estados brasileiros foram motivados a criar seus próprios sistemas de avaliação, para alcançarem o índice do Ideb, e que interferiam diretamente nos resultados da aprendizagem. Para Casassus (2009, p. 74), “é um erro assinalar que o êxito ou fracasso de uma política se mede pelo subir de pontos, numa medição que não mede o que se lhe atribui e que o sistema, tal como está concebido, não pode modificar”.

Há consideráveis discussões acerca da avaliação em larga escala e que, a cada ano, traz à tona a dinâmica que se instaura nas escolas, tanto para o monitoramento dos avanços do índice quanto no sentido de ser o meio principal para divulgação e execução das mudanças desejadas. Os reflexos desse acordo político influenciam a escola e por meio de monitoramento e de formas de regulação e de controle dos seus resultados, ampliou o discurso político que os testes padronizados e com respectivos resultados encontrados será possível identificar os pontos que merecem ser repensados e, a partir disso, realizar intervenções que possibilitem sanar as dificuldades apresentadas no contexto escolar e consequentemente buscar as mudanças necessárias na educação escolar, essas também tendem a reforçar a ideia de que é necessária a responsabilização nos resultados de avaliações de desempenho, mais diretamente sobre o aluno.

Para Paschoalino (2017, p. 58), “as avaliações externas tomaram vulto e corroboram à lógica internacional de controle”. Se a educação brasileira, sob a lente das diversas avaliações externas, configura o fracasso pelos índices encontrados, por outro lado, crescia a responsabilização de cada instituição para vencer os desafios de melhoria do desempenho. $\mathrm{O}$ balanço realizado pelo Inep, por meio do relatório do $2^{\circ}$ ciclo de monitoramento das metas do PNE, permite à consulta pública angariar sugestões acerca do acompanhamento da meta, tendo como base de referência o ano de 2018 (PASCHOALINO, 2017). 
Revista Educação e Políticas em Debate - v. 10, n. 1, p. 433-452, jan./abr. 2021 - ISSN 2238-8346

Articulando-se à análise da meta 07 , constata-se no documento que o Ideb dos anos iniciais do EF no Brasil segue uma trajetória crescente de 2007 a 2015, superando as metas fixadas para o período. Em 2015, o Ideb dos anos iniciais foi de 5,5, já a meta fixada para aquele ano era de 5,2. No que diz respeito ao Ideb dos anos finais do EF no Brasil, esse apresenta uma trajetória crescente no período de 2007 a 2015, sem, contudo, atingir, desde 2013, as metas fixadas. Em 2015, o Ideb dos anos finais foi de 4,5, abaixo da meta fixada para aquele ano $(4,7)$. Ao se considerarem as dimensões do Ideb - a taxa média de aprovação e o desempenho nas avaliações nacionais - no período, verifica-se um crescimento da taxa média de aprovação tanto nos anos iniciais quanto nos anos finais do EF. Nos anos iniciais, o crescimento foi maior: de 86,4\% em 2007 para 93,2\% em 2015, comparado ao dos anos finais: de 80,0\% para 85,8\% no mesmo período. $\mathrm{O}$ desempenho médio dos alunos do $5^{\circ}$ e do $9^{\circ}$ anos do $\mathrm{EF}$ em Língua Portuguesa e em Matemática também foi crescente (BRASIL, Inep, 2019, s/p).

Não obstante, o relatório indica que os resultados da Avaliação Nacional da Educação Básica (Aneb) de 2015 evidenciam a variação e a desigualdade existente em seu aprendizado. A análise da distribuição dos alunos pelos níveis de proficiência das escalas de Língua Portuguesa e de Matemática revela que há um quantitativo significativo de alunos cuja proficiência está situada nos níveis inferiores dessas escalas, indicando um menor aprendizado em termos de desenvolvimento das competências e das habilidades avaliadas.

Em relação à trajetória do Ideb do Ensino Médio no período de 2007 a 2015, essa aponta a estagnação desse índice a partir de 2011 (3,7). Em 2013 e 2015, o Ideb ficou abaixo das metas intermediárias fixadas para o $\operatorname{EM}$ (3,9 e 4,3, respectivamente). Ao considerar as dimensões do Ideb, observam-se, no ensino médio, "o aumento da taxa de aprovação no período (de 77,8\% em 2007 para 83,4\% em 2015) e uma tendência à estagnação no desempenho dos alunos, caracterizada pela oscilação da proficiência em Língua Portuguesa e diminuição da proficiência em Matemática”. (BRASIL, Inep, 2019, s/p).

Segundo Fernandes Neto (2009), o SAEB, aplicado em 2005, que testou conhecimentos de Português e Matemática, vem revelando os mais baixos índices de rendimento entre estudantes da $8^{\mathrm{a}}$ série do Ensino Fundamental e da $3^{\mathrm{a}}$ série do Ensino Médio desde sua primeira aplicação, em 1995, expressando a dificuldade e o fracasso das políticas educacionais dos últimos 12 anos, tanto do governo Fernando Henrique Cardoso (FHC) como do governo Lula/Haddad.

É verdade que ainda não temos indicadores capazes de traduzir a qualidade escolar em termos perfeitos ou mesmos satisfatórios na visão de Vieira (2007, p. 52). Aliás, a autora argumenta que talvez a complexidade da educação não permita a construção de um modelo perfeito. Entretanto, é possível começar pelos resultados disponíveis, e com eles trabalhar e ir aos 
poucos construindo uma cultura de avaliação. E questiona: seria essa uma tarefa simples? Certamente que não! Se fosse fácil, por certo, outros já teriam encontrado a fórmula do sucesso. Informações básicas como as taxas de escolarização relativas à Educação Infantil, ao Ensino Fundamental e ao Ensino Médio tendem a ser esquecidas na expansão da oferta, que, muitas vezes, caminha ao sabor das pressões da demanda e da capacidade de resposta do sistema (VIEIRA, 2007, p. 52).

Por meio da divulgação dos resultados da avaliação, instaurou-se a responsabilização da equipe da gestão, provocando efeitos na rotina e na organização do trabalho pedagógico da escola na busca da qualidade. Segundo Vieira (2007, p. 53), “tão importante quanto difundir resultados é criar condições para que as escolas se reconheçam nos dados, como mencionamos em momento anterior deste mesmo texto". Por essa razão, Vieira (2007) menciona que o tratamento das informações deve chegar a um nível de detalhe que ultrapasse quaisquer generalizações. Parte da afirmação de que a escola vai mal e cai no vazio se permanecer nesse nível e, por isso mesmo, é preciso ter resultados por escola e disponibilizá-los aos gestores escolares que permitem a eles terem uma atuação efetiva no cotidiano do trabalho escolar.

Frente às necessidades constituídas a partir deste contexto, é perceptível que para além das possibilidades da delimitação do reconhecimento do papel predominante das políticas oficiais, as quais, em absoluto, desconhecem a existência de inciativas antagônicas que ocorrem na própria prática escolar, essa questão polêmica vem suscitando discussões entre vertentes que prezam a valorização de fatores que poderiam estar interferindo no desempenho do aluno.

O Ideb está se colocando, cada vez mais, como um apêndice ao trabalho dos professores. Mas, mesmo tomando o índice referência, a discutível noção elaborada a partir dos seus resultados expressos por dados estatísticos somente. A preponderância em garantir a tão almejada qualidade em educação, o que podemos citar, a título de exemplo, a procura por problematizar as atuais condições de trabalho na escola e superar as deficiências o baixo desempenho das provas sistêmicas realizadas pelos estudantes, bem como as necessidades de apoio educacional nas escolas, não reduzindo apenas as similaridades das cobranças por números como vem sendo apresentado nos dias atuais.

Para Santos (2004, p. 1152), “uma avaliação do sistema de ensino que tem como referência o desempenho de indicadores estandardizados termina por não permitir formas mais flexíveis e diferenciadas de trabalho pedagógico”. Dito isso, Santos (2004) considera aquilo que não for possível de ser mensurado e diretamente observável, deixa de ter importância para esse tipo de avaliação. Ressalta-se, também, que, paradoxalmente, a proposta de tornar transparente o desempenho das pessoas e das instituições termina por obscurecer, em vez de revelar aspectos importantes do que ocorre no cotidiano das escolas. 
Revista Educação e Políticas em Debate - v. 10, n. 1, p. 433-452, jan./abr. 2021 - ISSN 2238-8346

À luz dessas orientações, é preciso cuidado sobre a efetividade política no que diz respeito ao mau desempenho educacional e as fragilidades do ensino. Os critérios de desempenho a serem traçados na gestão da escola pública, principalmente, ao se estabelecer diferenciações a patamares entre a melhor e a pior escola, assim como as mudanças significativas que apontam proporções de solução aos problemas escolares e críticas ao rendimento do aluno.

Os efeitos desses processos avaliativos apontam uma relação marcada por situações conflituosas que internalizam o desempenho dos estudantes da Educação Básica. A adoção de programas que priorizem os objetivos de qualidade para a gestão da escola, hoje desponta a democratização como elemento de relevância na educação. Na contramão das necessidades da educação, não é possível adequar uma polêmica em curso que atravessa o chão da escola e que vem sendo ameaçada pela meta de resolver a crise de qualidade da educação por meio da produtividade e da racionalidade econômica, face à legitimidade dos resultados satisfatórios que devem ser alcançados na gestão escolar. Isto nos leva a exigir estudos empíricos para sua compreensão e apropriação do processo de trabalho do professor, levando em consideração outros atributos ou fatores que contribuem para a qualidade da educação e que têm sido negligenciados pelas políticas avaliativas em questão.

\section{Considerações finais}

As questões iniciais, neste texto, visaram a descobrir qual seria a lógica e o discurso que está por trás do Ideb e que tem servido de referência para a medição da qualidade da educação. Indagou-se, também, se seria possível expressar sua existência e intencionalidade subjacentes a gestão escolar para resultados tangíveis a avaliação educacional e ao desempenho dos estudantes.

Verificou-se, por isso, que a meta 7 do PNE, particularmente quando visam a garantir o alcance do nível suficiente de aprendizado ante a legitimidade dos resultados satisfatórios, devem ser alcançados com intuito de garantir sucesso escolar.

Os dados do Ideb apontam que a meta 7 foi alcançada nos anos iniciais do Ensino Fundamental, mas ainda não foi atingida nos anos finais dessa etapa, nem no Ensino Médio, haja vista que os entes federados não têm capacidade orçamentária para executar a responsabilidade com a Educação Básica e o governo federal não está dando suporte suficiente, nem orçamentário nem técnico.

Cabe mencionar o aspecto propositivo de mudança, pois, apesar de não ser a tarefa da presente pesquisa, e sim apresentar, analisar o fenômeno investigado, consideramos que o 
Revista Educação e Políticas em Debate - v. 10, n. 1, p. 433-452, jan./abr. 2021 - ISSN 2238-8346 debate deva continuar em relação à dúvida se o índice tem sido considerado um indicador suficiente para realmente avaliar a qualidade da educação. Entretanto, mesmo que considerarmos o Ideb como passo introdutório e importante para avaliação da educação no país, relativizar os efeitos dos resultados obtidos pelo desempenho adquirido pelos alunos por meio de dados estatísticos deveria ter o cuidado ao designar uma escola de qualidade.

Essa forma de pressão sobre a escola tem sido a nova forma de regulação do sistema educativo, com realocação de suas atividades operacionais e pedagógicas das escolas públicas e da equipe escolar, visando atender a uma gestão por resultados nos moldes empresariais, criando a ilusão de que a escola poderá resolver todos os seus problemas e situações conflituosas no seu espaço.

Embora o Ideb não abarque todos os problemas que envolvem a situação da escola, não temos dificuldades em perceber a predileção pela lógica da gestão por resultados na sua utilização. Assim, pode-se afirmar que, na forma como Ideb vem sendo apresentado, a proposta merece ser estudada sob a perspectiva de confronto com as novas demandas feitas ao trabalho do professor, para que haja tamanha coexistência entre o que acontece em sala de aula de forma mais próxima numa perspectiva avaliativa do desempenho dos estudantes. O diagnóstico permite realizar a elaboração de qualquer plano de ação. Buscar a construção conjunta de alternativas para os problemas, que se apresenta no cotidiano escolar, se faz pertinente para uma gestão coletiva e democrática da escola.

A capacidade de intervenção nas escolas de baixo rendimento necessita de novas formas de trabalho docente que ofereçam pistas fortemente condicionadas à resolução de problemas. É necessário levá-los a refletir sobre as dificuldades específicas enfrentadas no cotidiano da sua escola, que lhes servem de apoio às mudanças necessárias a se fazer para que possam desempenhar seu trabalho de forma mais segura e favorecer a participação da gestão escolar. Nesse horizonte, rever as estratégias utilizadas pela equipe de gestão escolar, as maneiras de organizar e de gerir o trabalho escolar e ajudá-la com o suporte financeiro, por meio dos resultados obtidos pelo Ideb e identificados pelas orientações do PNE vislumbra a construção de vias para intervir em ações que as aproximem dos patamares ideais.

Tem-se, portanto, o desafio de realizar novas pesquisas, de contribuir para transformar essa relação por meio da valorização dos aspectos positivos e negativos relacionados aos processos avaliativos da escola e de conduzir melhores rendimentos escolares do aluno.

Buscando encerrar aqui essa discussão, o que geralmente ocorre nas escolas é a divulgação dos resultados de avaliações sem levar em conta os elementos que a compõem e que ainda necessitam ser discutidos, em especial pelas reformas neoliberais nas políticas de governo local. E como a gestão das escolas públicas o dilema existencial está relacionado à 
Revista Educação e Políticas em Debate - v. 10, n. 1, p. 433-452, jan./abr. 2021 - ISSN 2238-8346 busca por resultados no rendimento do aluno, haverá, contudo, a necessidade de consenso e de diálogo para que ambos - Estado e profissionais da educação escolar - gerem um sentimento de equilíbrio, comprometidos com uma escola de qualidade, democrática e com resultados qualitativos.

\section{Referências}

ABREU, G. A. Acordo de resultados e sistema mineiro de avaliação: estudo de caso em três escolas estaduais da Superintendência Regional de Ensino de Caxambu - MG. Dissertação de Mestrado profissional em Gestão e Avaliação da Educação Pública. Faculdade de Educação, Universidade Federal de Juiz de Fora, 2013. DOI: https://doi.org/10.11606/d.96.2011.tde-18012012-104955.

AFONSO, A. J. Mudanças no Estado-avaliador: comparativismo internacional e teoria da modernização revisitada. Revista Brasileira de Educação, v.18, n.53, p. 267-284, abr/jun. 2013. ISSN 1413-2478. DOI: https://doi.org/10.1590/s1413-24782013000200002.

AFONSO, A. J. Para uma conceitualização alternativa de accountability em educação. Educação e Sociedade [on line], 2012, vol. 33, n. 119, pp. 471-484. ISSN 1678-4626.

ALAVARSE, O. M.; BRAVO, M. H., MACHADO, C. Avaliações externas e qualidade na educação básica: articulações e tendências. Estudos em Avaliação Educacional, São Paulo, v. 24, n. 54, p. 12-31, jan./abr. ISSN 0103-6813. Disponível em: http://www.fcc.org.br/pesquisa/publicacoes/eae/arquivos/1783/1783.pdf. Acesso em: maio de 2018.

ÁVALOS, B. La formación inicial docente em Chile: Tensiones entre políticas de apoyo e control. Estudios Pedagógicos, v. XL, Número Especial 1, p. 11-28, 2014. ISSN 0718-0705. DOI: https://doi.org/10.4067/s0718-07052014000200002.

BECKER, F. R. Avaliação educacional em larga escala: a experiência brasileira. Revista iberoamericana de educación, n. 53, 2010. ISSN 1022-6508.

BELO, F.; AMARAL, N. C. IDEB da Escola: a aferição da qualidade do ensino tem sido referencial para se (re) pensar a educação municipal? Revista Educação e Políticas em Debate, v. 2, n. 2, jul./dez. p. 339-353, 2013. ISSN 2238-8346. DOI: https://doi.org/10.14393/REPOD.issn.2238-8346.

BRASIL, Lei n. 13.005, 25 de junho de 2014. Aprova o Plano Nacional de Educação PNE. Diário Oficial da União, Brasília, DF, 26 de junho de 2014. Edição Extra. Disponível em http://www.planalto.gov.br/CCivilo3/ato2011-2014/leiqL13005.htm. Acesso em: 18 maio de 2019.

BRASIL, Ministério da Educação. Planejando a próxima década: conhecendo as 20 metas do Plano Nacional de Educação. Secretaria de Articulação com os Sistemas de Ensino (MEC/SASE), 2014. 
Revista Educação e Políticas em Debate - v. 10, n. 1, p. 433-452, jan./abr. 2021 - ISSN 2238-8346

BRASIL. Ministério da Educação. Resolução $C N E / C P N^{o}$ 2, de 20 de dezembro de 2019. Define as Diretrizes Curriculares Nacionais para formação inicial de professores e institui a Base Nacional Comum (BNC-formação). Brasília: DF, 2019.

BRASIL. Instituto Nacional de Estudos Educacionais Anísio Teixeira. Relatório do $2^{\circ}$ ciclo de monitoramento das metas do Plano Nacional de Educação - 2018. 2. Ed. Brasília, DF: Inep, 2019. ISBN 978-65-81041-01-4 (on line).

CASASSUS, J. Uma nota crítica sobre a avaliação estandartizada: a perda da qualidade e a segmentação social. Sísifo: Revista de Ciência da Educação, pp. 71-79, 2009. ISSN 1646-4990.

CURY, C. R. Jamil. Sistema nacional de educação: desafio para uma educação igualitária e federativa. Educação e Sociedade, v. 29, n. 105, p. 1187-1209, dez./2008. ISSN 1678-4626. DOI: https://doi.org/10.1590/s0101-73302008000400012.

EVANGELISTA, O.; SHIROMA, E.O. Professor: protagonista e obstáculo da reforma. Educação e Pesquisa, v. 33, n. 3, p. 531-541, set./dez., 2007. ISSN 1678-4634. DOI: https://doi.org/10.1590/S1517-97022007000300010.

FERREIRA, L.A. A Avaliação no Plano Nacional de Educação (2014-2024). Meta: Avaliação, v.8, n. 24, 2016. ISSN 2175 -2753. DOI: http://dx.doi.org/10.22347/2175-2753v8i24.1138

FERNANDES NETO, E. O fracasso dos planos neoliberais na educação brasileira. In: COSTA, Áurea, NETO, Edgar Fernandes, SOUZA, Gilberto. A proletarização do professor: neoliberalismo na educação. São Paulo: Editora: Instituto José Luís e Rosa Sundermann, 2009, p. 11-57. ISSN 1517-4689.

FIGUEIREDO, I. M. Z. Os projetos financiados pelo Banco Mundial para o Ensino Fundamental no Brasil. Educação \& Sociedade, Campinas, vol. 30, n. 109, p. 1123-1138, set./dez., 2009. ISSN 1678-4626. DOI: https://doi.org/10.1590/s010173302009000400010.

GATTI, B. A. Possibilidades e fundamentos de avaliações em larga escala: primórdios e perspectivas contemporâneas. In: Bauer, A.; Gatti B. A.; Tavares, M. R. (Org). Vinte e cinco anos de avaliação de sistemas educacionais no Brasil: origem e pressupostos. Florianópolis: Insular/FCC, 2v, 2013. ISBN-10:8574747122.

LÜCK, H. Dimensões da gestão escolar e suas competências. Curitiba: Positivo, 2009. ISBN: 97885-385-0027-8.

MANCEBO, D. Agenda de pesquisa e opções teórico-metodológicas nas investigações sobre trabalho docente. Educação E Sociedade, v. 28, n. 99, p. 466-482, maio/ago., 2007. ISSN 1678-4626. DOI: https://doi.org/10.1590/s0101-73302007000200009.

OBSERVATÓRIO do PNE. Disponível em: https://www.observatoriodopne.org.br. Acesso em: 14 jun. 2020.

PASCHOAlinO, J. B. de Q. Desafios da gestão escolar. Belo Horizonte: Studium Eficaz, 2017. ISBN: 978-85-93657-00-9. 
Revista Educação e Políticas em Debate - v. 10, n. 1, p. 433-452, jan./abr. 2021 - ISSN 2238-8346

RODRIGUES, M. M. Reflexões acerca da escola e do conhecimento escolar, em: França, Magna; Bezerra, Maura Costa (orgs.). Política educacional: gestão e qualidade de ensino. Brasília: Liber Livro, 2009, p. 101 - 115. ISBN: 978-85-98843-94-0.

SANTOS, L. L. C. P. Formação de professores na cultura do desempenho. Educação e Sociedade, vol. 25, n. 89, p. 1145-1157, set./dez., 2004. ISSN 1678-4626. DOI: https://doi.org/10.1590/S0101-73302004000400004.

SILVA, R. P. A atuação do gestor na utilização dos resultados do SADAEM em duas escolas estaduais da coordenadoria distrital de Educação. Dissertação de Mestrado profissional em Gestão e Avaliação da Educação Pública. Faculdade de Educação. Universidade Federal de Juiz de Fora, 2015.

TEllo, C., AlMEIDA, M. L. P. Políticas educativas e profissionalização docente na América Latina. Revista Lusófona de Educação, n. 26, p. 161-174, 2014. ISSN 1645-7250.

TORRES, R. M. Balance y perspectiva de la formación docente en América Latina. Ciência y Sociedade, v. XXV, n. 3, p. 368-394, 1996. ISSN 0378-7680. DOI: https://doi.org/10.22206/cys.2000.v25i3.pp368-94.

VIEIRA, S. L. Gestão, avaliação e sucesso escolar: recortes da trajetória cearense. Estudos Avançados, vol. 2, n. 60, São Paulo, maio/ago., 2007. ISSN 1806-9592. Disponível em: http://www.scielo.br/scielo.php? script=sci_arttext\&pid=S0103-40142007000200004.

Acesso em: 23 jun. 2016. DOI: https://doi.org/10.1590/s0103-40142007000200004. 